IP Periodica Polytechnica Civil Engineering

\author{
62(4), pp. 930-938, 2018 \\ https://doi.org/10.3311/PPci.11891 \\ Creative Commons Attribution (i)
}

RESEARCH ARTICLE

\section{Bending Response of Composite Material Plates with Specific Properties, Case of a Typical FGM "Ceramic/Metal" in Thermal Environments}

\author{
Abdelrahmane Bekaddour Benyamina ${ }^{1 *}$, Bachir Bouderba ${ }^{2}$, \\ Abdelkader Saoula ${ }^{1}$
}

Received 30 December 2017; Revised 27 March 2018; Accepted 09 May 2018

\begin{abstract}
The rapid development of composite materials and structures in recent years has attracted the increased attention of many engineers and researchers. These materials are widely used in aerospace, military, mechanical, nuclear, marine, optical, electronic, chemical, biomedical, energy sources, automotive fields, ship building and structural engineering industries. In conventional laminate composite structures, homogeneous elastic plate are bonded together to obtain improved mechanical and thermal properties. However, the abrupt change in material properties across the interface between the different materials can cause strong inter-laminar stresses leading to delamination, cracking, and other damage mechanisms at the interface between the layers. To remedy these defects, functionally graded materials (FGM) are used, in which the properties of materials vary constantly. The purpose of this paper is to analyze the thermomechanical bending behavior of functionally graded thick plates (FGM) made in ceramic/metal. This work presents a model that employed a new transverse shear function. The numerical results obtained by the present analysis are presented and compared with those available in the literature (classical, first-order, and other higher-order theories). It can be concluded that this theory is effective and simple for the static analysis of composite material plates with specific properties "Case of a typical FGM (ceramic/metal)" in thermal environments.
\end{abstract}

\section{Keywords}

FGM, shear function, mechanical loads, thermal behavior

\footnotetext{
1 Department of Civil Engineering,

Faculty of Applied Sciences,

Ibn Khaldoun University,

BP 78 Zaaroura, P.B. 14000, Tiaret, Algeria

2 Department of Science and Technology,

Institute of Science and Technology,

El-Wancharissi University Center, Tissemsilt,

Route de BOUGARA, Ben Hamouda, P.B. 38004, Tissemsilt, Algeria

* Corresponding author, email: beny104@gmail.com
}

\section{Introduction}

For the first time, in 1984-1985, a group of Japanese scientist proposed the concept of FGM. Five years later, the first international conference [1] was held at Sendai-City in Japan. The interest was such that a rapid progress of FGM research in Japan was noticed from 1984 to 1996. At the beginning FGM was designed as a thermal barrier material for aerospace and fusion reactors applications [2]. Later, FGMs were developed for the military, automotive, biomedical and semiconductor industries, and as a general structural element in high thermal environments temperature-resistant materials. Functionally gradient materials (FGMs) are inhomogeneous at the microscopic scale, in which the mechanical properties vary regularly and continuously from one surface to another. This is done by gradually varying the volume fraction of the constituent materials; these materials are made from a mixture of ceramic and metal or a combination of different materials. The ceramic constituent provides a high temperature resistant material due to its low thermal conductivity and protects the metal from oxidation. The ductile metal component, on the other hand, prevents fracture caused by high temperature gradient stresses in a very short period of time. In addition, a mixture of a ceramic and a metal with a continuously varying volume fraction can be easily manufactured Surash et al [3], Plindera et al [4], [5] and Markworth et al [6]. A number of journals dealing with various aspects of the FGM have been published in recent years [7], [8], and [9]. Proceedings of international seminar on FGM also shed light on the latest research in these materials, their manufacture, Biest et al [10], studies of FGM plates on mechanics, thermal properties and thermo-mechanical response of FGM plates; Reddy [11], Reddy and Chin [12], Vel and Batra [13, 14], Cheng and Batra [15]. A recent critical review of thermal analysis of FGM plates has been published by Swaminathan et al [16].

In this paper a new exponential refined shear deformation plate theory is employed. The exponential function in terms of thickness coordinates is used in the displacement field to consider the shear deformations. The originality of the theory is that it does not require a shear correction factor, satisfying the 


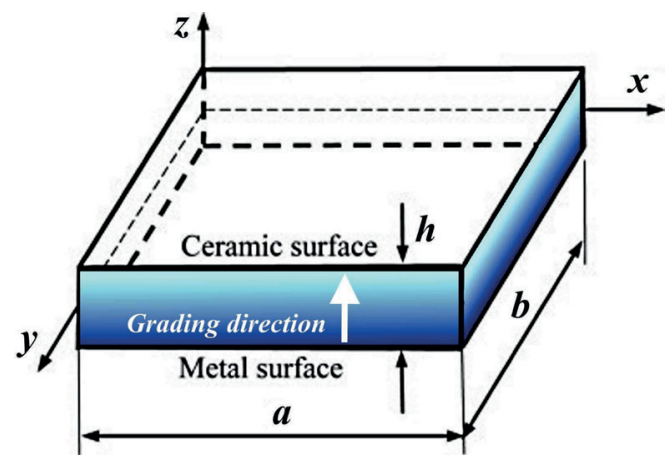

Fig. 1 Geometry and coordinate system of the FGM rectangular plate

nullity of shear stress at the upper and lower surfaces of the plate, the unknown functions number is only four, while five or more in the case of other shear deformation theories [16]. Numerical examples are presented to illustrate the accuracy and efficiency of this theory by comparing the results obtained with those calculated using various other theories. When Aydogdu [17] compared various HSDPT's (Higher-order Shear Deformation Plate Theories) with available 3D analysis, it has been pointed out that, while the parabolic shear deformation proposed by Reddy [18] and hyperbolic shear deformation theory proposed by Soldatos [19] plate theories yields more accurate predictions for natural frequencies and buckling loads, the transverse displacements and stresses are best predicted by ESDT (the exponential shear deformation plate theory) proposed by Karama et al [20].

\section{Theoretical formulation}

Consider a rectangular plate in FGM of thickness $h$, a length $a$ according to the $\mathrm{x}$-direction, and has a width $b$ following the $y$-direction, as shown in the Fig. 1. The plate material properties varying gradually across the thickness $(h)$, from the bottom surface in metal $(z=-h / 2)$ to the top surface in ceramic $(z=h / 2)$.

The present theory function is based on (ESDPT) the exponential shear deformation plate theory proposed by Karama et al [20], it is employed in FGM beams context by Osfero et al [21]. This function Eq. (1) is used as an exponential distribution of the shear transverse stresses, it satisfies the nullity of these stresses on the upper and lower plate surfaces without using shear correction factors. The unknown functions number is only four, while five or more in the case of other shear deformation theories [16], Table 1.

The proposed present theory based on the assumption that the axial and transverse displacements consist of one bending and one shear part so that the bending component does not contribute to the shear forces and so, the shear component does not contribute to the bending moments [22].

\subsection{Basic assumptions}

For the present theory the following assumptions are used:

- The displacements are small in comparison with the plate thickness and, therefore, strains involved are infintesimal.
Table 1 Plate theories displacement models.

\begin{tabular}{lcc}
\hline Model & $\begin{array}{c}\text { Transverse shear } \\
\text { function }\end{array}$ & Unknown functions \\
\hline CPT (classical plate theory) & $\psi(z)=0$ & 3 \\
FSDPT (Reissner [23]) & $\psi(z)=z$ & 5 \\
PSDPT (Reddy [18]) & $\psi(z)=z\left(1-\frac{4 z^{2}}{3 h^{2}}\right)$ & 5 \\
SSDPT(Touratier [24],[25]) & $\psi(z)=\frac{h}{\pi} \sin \left(\frac{\pi z}{h}\right)$ & 5 \\
ESDPT (Karama et al [20]) & $\psi(z)=z e^{-2\left(\frac{z}{h}\right)^{2}}$ & 5 \\
Present (RESDPT) & $\psi(z)=z-z e^{-2\left(\frac{z}{h}\right)^{2}}$ & 4 \\
\hline
\end{tabular}

- The transverse displacement $w$ includes two components of bending $w_{b}$ and shear $w_{s}$. These components are functions of coordinates $x, y$ only.

- The transverse normal stress $\sigma_{z}$ is negligible in comparison with in-plane stresses $\sigma_{x}$ and $\sigma_{y}$.

- The displacement $u$ in x-direction and $v$ in y-direction consist of extension, bending and shear components.

\subsection{Kinematics}

In this paper a new exponential refined shear deformation plate theory is employed. The exponential function in terms of thickness coordinates is used in the displacement field to consider the shear deformations. The originality of the theory is that it does not require a shear correction factor (Table 1), satisfying the nullity of shear stress at the upper and lower surfaces of the plate, the proposed shear function is [21]:

$$
\psi(z)=z-z e^{-2\left(\frac{z}{h}\right)^{2}}
$$

Based on the above assumptions, the displacement field is obtained as follows:

$$
\begin{gathered}
U(x, y, z)=u_{0}(x, y)-z \frac{\partial w_{b}}{\partial x}-\psi(z) \frac{\partial w_{s}}{\partial x} \\
V(x, y, z)=v_{0}(x, y)-z \frac{\partial w_{b}}{\partial y}-\psi(z) \frac{\partial w_{s}}{\partial y} \\
W(x, y, z)=w_{b}(x, y)+w_{s}(x, y)
\end{gathered}
$$

The kinematic relations can be obtained as follows:

$$
\left\{\begin{array}{c}
\varepsilon_{x} \\
\varepsilon_{y} \\
\gamma_{x y}
\end{array}\right\}=\left\{\begin{array}{c}
\varepsilon_{x}^{0} \\
\varepsilon_{y}^{0} \\
\gamma_{x y}^{0}
\end{array}\right\}+z\left\{\begin{array}{c}
k_{x}^{b} \\
k_{y}^{b} \\
k_{x y}^{b}
\end{array}\right\}+\psi(z)\left\{\begin{array}{c}
k_{x}^{s} \\
k_{y}^{s} \\
k_{x y}^{s}
\end{array}\right\},
$$

And :

$$
\left\{\begin{array}{l}
\gamma_{y z} \\
\gamma_{x z}
\end{array}\right\}=\xi(z)\left\{\begin{array}{l}
\gamma_{y z}^{s} \\
\gamma_{x z}^{s}
\end{array}\right\}
$$


Where :

$$
\begin{gathered}
\left\{\begin{array}{c}
\varepsilon_{x}^{0} \\
\varepsilon_{y}^{0} \\
\gamma_{x y}^{0}
\end{array}\right\}=\left\{\begin{array}{c}
\frac{\partial u_{0}}{\partial x} \\
\frac{\partial v_{0}}{\partial x} \\
\frac{\partial u 0}{\partial y}+\frac{\partial v_{0}}{\partial x}
\end{array}\right\},\left\{\begin{array}{l}
k_{x}^{b} \\
k_{y}^{b} \\
k_{x y}^{b}
\end{array}\right\}=\left\{\begin{array}{c}
-\frac{\partial^{2} w_{b}}{\partial x^{2}} \\
-\frac{\partial^{2} w_{b}}{\partial y^{2}} \\
-2 \frac{\partial^{2} w_{b}}{\partial x \partial y}
\end{array}\right\} \\
\left\{\begin{array}{l}
\gamma_{y z}^{s} \\
\gamma_{x z}^{s}
\end{array}\right\}=\left\{\begin{array}{l}
\frac{\partial w_{s}}{\partial y} \\
\frac{\partial w_{s}}{\partial x}
\end{array}\right\}\left\{\begin{array}{l}
k_{x}^{s} \\
k_{y}^{s} \\
k_{x y}^{s}
\end{array}\right\}=\left\{\begin{array}{c}
\partial x^{2} \\
-\frac{\partial^{2} w_{s}}{\partial y^{2}} \\
-2 \frac{\partial^{2} w_{s}}{\partial x \partial y}
\end{array}\right\}
\end{gathered}
$$

Where $\xi(z)$ is the considred warping funtion derivative (1), its variation along the thickness is dipcted in Fig. 2, it is defined as follows:

$$
\xi(z)=1-\frac{d \psi(z)}{d z}
$$

\subsection{Constitutive equations}

P-FGM is one of the most favorable models for FGMs. Effective material properties such as Young's modulus E, shear modulus $G$, mass density $\rho$ and thermal expansions $\alpha$ are assumed to vary continuously in the depth direction according to power-low. Poisson's ratio $v$ is assumed to be constant through the thickness of the plate, Dalale et al [26] states that the effect of this coefficient is not important as that of Youg modulus in deformations.

The effective material properties of FG plate with two kind of porosities that distributed identical in two phases of ceramic and metal can be expressed by using the modified rule of mixture as [27], [28] :

$$
P(z)=P_{C}\left(V_{C}-\frac{\alpha^{\prime}}{2}\right)+P_{M}\left(V_{M}-\frac{\alpha^{\prime}}{2}\right)
$$

In which $P_{C}$ and $P_{M}$ are the corresponding properties of ceramics and metal, respectively, and $\alpha^{\prime}$ is the volume fraction of porosities $\left(\alpha^{\prime}<<1\right)$, for perfect FGM $\alpha^{\prime}$ is set to zero, $V_{C}$ and $V_{M}$ are the volume fraction of ceramic and metal that are attached as [29], [30] and [31]:

$$
V_{C}=\left(\frac{1}{2}+\frac{z}{h}\right)^{p}, V_{C}+V_{M}=1
$$

In this paper the material properties $P(z)$ are assumed to vary continuously through the depth of the plate by a power mixture law [3], [32], [33] and [34], as follows:

$$
P(z)=P_{M}+\left(P_{C}-P_{M}\right) V_{C}
$$

Where $p$ is the volume fraction exponent or power indice in P-FGMs, which takes values higher or equal to zero.

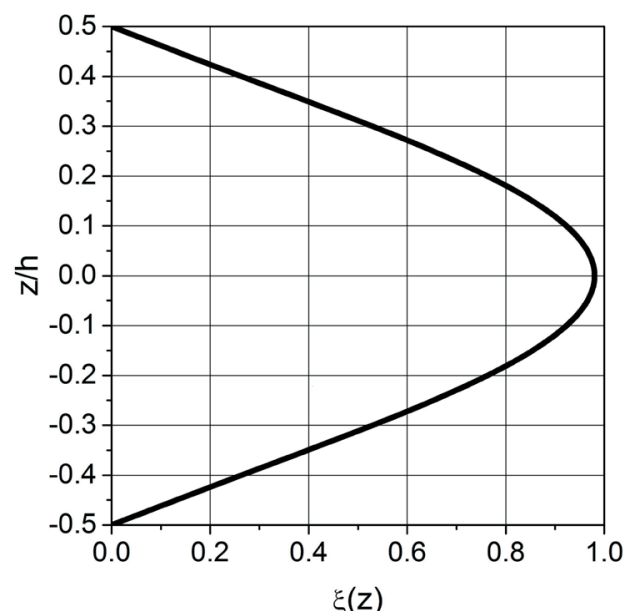

Fig. 2 Warping funtion derivative variation along the non-dimensional width $z / h$.

Using the material properties (12), the linear constitutive relations are:

$$
\begin{gathered}
\left\{\begin{array}{c}
\sigma_{x} \\
\sigma_{y} \\
\tau_{x y}
\end{array}\right\}=\left[\begin{array}{ccc}
Q_{11} & Q_{12} & 0 \\
Q_{12} & Q_{22} & 0 \\
0 & 0 & Q_{66}
\end{array}\right]\left\{\begin{array}{c}
\varepsilon_{x}-\alpha \Delta T \\
\varepsilon_{y}-\alpha \Delta T \\
\gamma_{x y}
\end{array}\right\} \\
\left\{\begin{array}{l}
\tau_{y z} \\
\tau_{z x}
\end{array}\right\}=\left[\begin{array}{cc}
Q_{44} & 0 \\
0 & Q_{55}
\end{array}\right]\left\{\begin{array}{l}
\gamma_{y z} \\
\gamma_{z x}
\end{array}\right\}
\end{gathered}
$$

Where $\left(\sigma_{x}, \sigma_{y}, \tau_{x y}, \tau_{y z}, \tau_{y x}\right)$ and $\left(\varepsilon_{x}, \varepsilon_{y}, \gamma_{x y}, \gamma_{y z}, \gamma_{z x}\right)$ are the terms of the stresses and deformations, respectively. The stiffness coefficients can be expressed by:

$$
\begin{gathered}
Q_{11}=Q_{22}=\frac{E(z)}{1-v^{2}}, Q_{12}=\frac{v E(z)}{1-v^{2}}, \\
Q_{44}=Q_{55}=Q_{66}=\frac{E(z)}{2(1+v)},
\end{gathered}
$$

A polynomial temperature distribution applied through the thickness $z$ is considred here [26], it is a combanation of three parts, a constant in $T_{1}$, a linear in $T_{2}$ and sinusoidal in $T_{3}$, as follows:

$$
T(x, y, z)=T_{1}(x, y)+\frac{z}{h} T_{2}(x, y)+\frac{1}{\pi} \sin \left(\frac{\pi z}{h}\right) T_{3}(x, y),
$$

In Eq. (13), $\Delta T=T-T_{0}$ in which $T_{0}$ is the reference temperature.

\subsection{Governing equations}

The governing equations of equilibrium can be derived by using the principale of virtual work, which is expressed in this case as follows:

$$
\begin{aligned}
& \int_{-h / 2}^{h / 2} \int_{\Omega}\left[\sigma_{x} \cdot \delta \varepsilon_{x}+\sigma_{y} \cdot \delta \varepsilon_{y}+\tau_{x y} \cdot \delta \gamma_{x y}\right. \\
& \left.+\tau_{y z} \cdot \delta \gamma_{y z}+\tau_{x z} \cdot \delta \gamma_{x z}\right] d \Omega d z-\int_{\Omega} q \cdot \delta w d \Omega=0
\end{aligned}
$$

Where $\Omega$ is the top surface and $q$ is a distributed mechanical loads on it. 


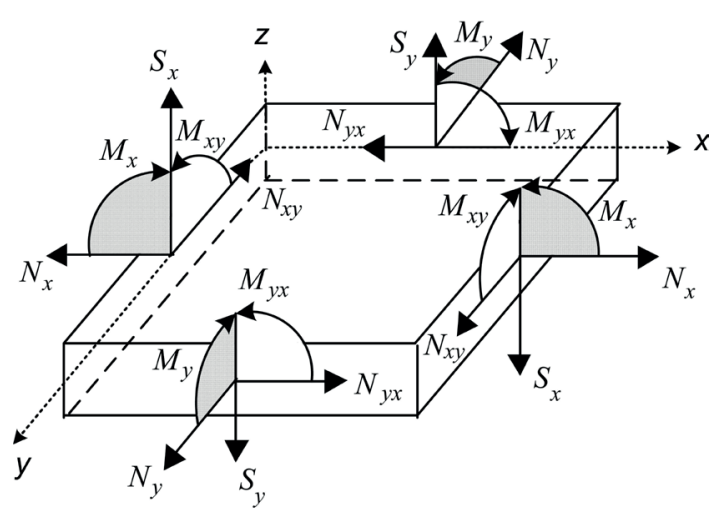

Fig. 3 Stresses resultants of the FGM plate

Substituting Eqs. (5-6) and (13-14) into Eq. (18) and integrating through the thickness of the plate, Eq. (18) can be rewritten as [32], [35]:

$$
\begin{aligned}
& \iint\left[N_{x} \delta \varepsilon_{x}^{0}+N_{y} \delta \varepsilon_{y}^{0}+N_{x y} \delta \varepsilon_{x y}^{0}\right. \\
& +M_{x}^{b} \delta k_{x}^{b}+M_{y}^{b} \delta k_{y}^{b}+M_{x y}^{b} \delta k_{x y}^{b}+M_{x}^{s} \delta k_{x}^{s} \\
& +M_{y}^{s} \delta k_{y}^{s}+M_{x y}^{s} \delta k_{x y}^{s}+S_{y x}^{s} \delta \gamma_{y z}^{s} \\
& \left.+S_{x z}^{s} \delta \gamma_{x z}^{s}\right] d x d y-\int q \cdot\left(\delta w_{b}+\delta w_{s}\right) d x d y=0
\end{aligned}
$$

Stresse resultants $N, M$, and $S$ in Fig. 3 are defined by:

$$
\begin{gathered}
\left\{\begin{array}{ccc}
N_{x}, & N_{y}, & N_{x y} \\
M_{x}^{b}, & M_{y}^{b}, & M_{x y}^{b} \\
M_{x}^{s}, & M_{y}^{s}, & M_{x y}^{s}
\end{array}\right\}=\int_{-h / 2}^{h / 2}\left(\sigma_{x}, \sigma_{y}, \tau_{x y}\right)\left\{\begin{array}{c}
1 \\
z \\
\xi(z)
\end{array}\right\} d z, \\
\left(S_{x z}^{s}, S_{y z}^{s}\right)=\int_{-h / 2}^{h / 2}\left(\tau_{x z}, \tau_{y z}\right) \xi(z) d z .
\end{gathered}
$$

Substituting Eqs. (13-14) into Eqs. (20-21) and integrating through the thickness of the plate, the stress resultants are in Eqs. (22-23) respectively, as follows:

$$
\left\{\begin{array}{c}
N \\
M^{b} \\
M^{s}
\end{array}\right\}=\left[\begin{array}{ccc}
A & B & B^{s} \\
B & D & D^{s} \\
B^{s} & D^{s} & H^{s}
\end{array}\right]\left\{\begin{array}{c}
\varepsilon \\
k^{b} \\
k^{s}
\end{array}\right\}-\left\{\begin{array}{c}
N^{T} \\
M^{b T} \\
M^{s T}
\end{array}\right\}
$$

Where :

$$
\begin{aligned}
& N=\left\{N_{x}, N_{y}, N_{x y}\right\}^{t}, M^{b}=\left\{M_{x}^{b}, M_{y}^{b}, M_{x y}^{b}\right\}^{t}, \\
& M^{s}=\left\{M_{x}^{s}, M_{y}^{s}, M_{x y}^{s}\right\}^{t}, N^{T}=\left\{N_{x}^{T}, N_{y}^{T}, 0\right\}^{t}, \\
& M^{b T}=\left\{M_{x}^{b T}, M_{y}^{b T}, 0\right\}^{t}, M^{s T}=\left\{M_{x}^{s T}, M_{y}^{s T}, 0\right\}^{t}, \\
& k^{b}=\left\{k_{x}^{b}, k_{y}^{b}, k_{x y}^{b}\right\}^{t}, k^{s}=\left\{k_{x}^{s}, k_{y}^{s}, k_{x y}^{s}\right\}^{t}, \varepsilon=\left\{\varepsilon_{x}^{0}, \varepsilon_{y}^{0}, \gamma_{x y}^{0}\right\}^{t},
\end{aligned}
$$

Extensional and bending stiffness $A, B$ and transverse shear stiffness coupling $B^{S}, D^{\mathrm{S}}$ and $H^{S}$, are defined as follows:

$$
\begin{aligned}
A & =\left[\begin{array}{ccc}
A_{11} & A_{12} & 0 \\
A_{12} & A_{22} & 0 \\
0 & 0 & A_{66}
\end{array}\right], B=\left[\begin{array}{ccc}
B_{11} & B_{12} & 0 \\
B_{12} & B_{22} & 0 \\
0 & 0 & B_{66}
\end{array}\right], \\
D & =\left[\begin{array}{ccc}
D 11 & D_{12} & 0 \\
D_{12} & D_{22} & 0 \\
0 & 0 & D_{66}
\end{array}\right], B^{s}=\left[\begin{array}{ccc}
B_{11}^{s} & B_{12}^{s} & 0 \\
B_{12}^{s} & B_{22}^{s} & 0 \\
0 & 0 & B_{66}^{s}
\end{array}\right], \\
D^{s} & =\left[\begin{array}{ccc}
D_{11}^{s} & D_{12}^{s} & 0 \\
D_{12}^{s} & D_{22}^{s} & 0 \\
0 & 0 & D_{66}^{s}
\end{array}\right], H^{s}=\left[\begin{array}{ccc}
H_{11}^{s} & H_{12}^{s} & 0 \\
H_{12}^{s} & H_{22}^{s} & 0 \\
0 & 0 & H_{66}^{s}
\end{array}\right],
\end{aligned}
$$

And the shear stress resultants are :

$$
\left\{\begin{array}{l}
S_{x z}^{s} \\
S_{y z}^{s}
\end{array}\right\}=\left[\begin{array}{cc}
A_{44}^{S} & 0 \\
0 & A_{55}^{S}
\end{array}\right]\left\{\begin{array}{l}
\gamma_{y z} \\
\gamma_{x z}
\end{array}\right\}
$$

With $A_{i j}, B_{i j}$, etc, are the stifness matrix terms of the plate, defined by:

$$
\left\{\begin{array}{lll}
A_{11} & B_{11} & D_{11} \\
A_{12} & B_{12} & D_{12} \\
A_{66} & B_{66} & D_{66}
\end{array}\right\}=\int_{-h / 2}^{h / 2} Q_{11}\left(1, z, z^{2}\right)\left\{\begin{array}{c}
1 \\
v \\
\frac{1-v}{2}
\end{array}\right\} d z
$$

$$
\left\{\begin{array}{lll}
B_{11}^{s} & D_{11}^{s} & H_{11}^{s} \\
B_{12}^{s} & D_{12}^{s} & H_{12}^{s} \\
B_{66}^{s} & D_{66}^{s} & H_{66}^{s}
\end{array}\right\}=\int_{-h / 2}^{h / 2} Q_{11} \psi(z)(1, z, \psi(z))\left\{\begin{array}{c}
1 \\
v \\
\frac{1-v}{2}
\end{array}\right\} d z
$$

And

$$
\begin{aligned}
& \left(A_{22}, B_{22}, D_{22}\right)=\left(A_{11}, B_{11}, D_{11}\right), \\
& \left(B_{22}^{s}, D_{22}^{s}, H_{22}^{s}\right)=\left(B_{11}^{s}, D_{11}^{s}, H_{11}^{s}\right) \\
& A_{44}^{s}=A_{55}^{s}=\int_{-h / 2}^{h / 2} \frac{E(z)}{2(1+v)}[\xi(z)]^{2} d z,
\end{aligned}
$$

Membrane resultants, flexural moments and additional shear moments, $N_{x}^{T}=N_{y}^{T}, M_{x}^{b T}=M_{y}^{b T}$ and $M_{x}^{s T}=M_{y}^{s T}$, Eq. (15), due to thermal loads are defined respectively by:

$$
\left\{\begin{array}{c}
N_{x}^{T} \\
M_{x}^{b T} \\
M_{x}^{s T}
\end{array}\right\}=\int_{-h / 2}^{h / 2} \frac{E(z)}{1-v} \alpha(z) T\left\{\begin{array}{c}
1 \\
z \\
\psi(z)
\end{array}\right\} d z,
$$

The governing equations of equilibrium can derived from equation Eq. (19) by integration the displacement gradients by parts and setting the coefficients $\delta u_{0}, \delta v_{0}$ and $\delta w_{0}$ to zero. Thus one can obtain the equilibrium equations associated with the present shear deformation theory: 


$$
\begin{aligned}
& \delta u_{0}: \quad \frac{\partial N_{x}}{\partial x}+\frac{\partial N_{x y}}{\partial y}=0 \\
& \delta v_{0}: \quad \frac{\partial N_{x y}}{\partial x}+\frac{\partial N_{y}}{\partial y}=0 \\
& \delta w_{b}: \quad \frac{\partial^{2} M_{x}^{b}}{\partial x^{2}}+2 \frac{\partial^{2} M_{x y}^{b}}{\partial x \partial y}+\frac{\partial^{2} M_{y}^{b}}{\partial y^{2}}+q=0 \\
& \delta w_{s}: \quad \frac{\partial^{2} M_{x}^{s}}{\partial x^{2}}+2 \frac{\partial^{2} M_{x y}^{s}}{\partial x \partial y}+\frac{\partial^{2} M_{y}^{s}}{\partial y^{2}}+\frac{\partial S_{x z}^{s}}{\partial x}+\frac{\partial S_{y z}^{s}}{\partial y}+q=0
\end{aligned}
$$

Substituting Eqs. (22-23) into Eq. (28), we obtain the following equations:

$$
\begin{gathered}
A_{11} d_{11} u_{0}+A_{66} d_{22} u_{0}+\left(A_{12}+A_{66}\right) d_{12} v_{0} \\
-B_{11} d_{111} w_{b}-\left(B_{12}+2 B_{66}\right) d_{122} w_{b} \\
-\left(B_{12}^{s}+2 B_{66}^{s}\right) d_{122} w_{s}-B_{11}^{s} d_{111} w_{s}=f_{1}, \\
A_{22} d_{22} v_{0}+A_{66} d_{11} v_{0}+\left(A_{12}+A_{66}\right) d_{12} u_{0} \\
-B_{22} d_{222} w_{b}-\left(B_{12}+2 B_{66}\right) d_{112} w_{b} \\
-\left(B_{12}^{s}+2 B_{66}^{s}\right) d_{112} w_{s}-B_{22}^{s} d_{222} w_{s}=f_{2}, \\
B_{11} d_{111} u_{0}+\left(B_{12}+2 B_{66}\right) d_{122} u_{0} \\
+\left(B_{12}+2 B_{66}\right) d_{112} v_{0}+B_{22} d_{222} v_{0} \\
-D_{11} d_{1111} w_{b}-2\left(D_{12}+2 D_{66}\right) d_{1122} w_{b} \\
-D_{22} d_{2222} w_{b}-D_{11}^{s} d_{1111} w_{s} \\
-2\left(D_{12}^{s}+2 D_{66}^{s}\right) d_{1122} w_{s}-D_{22}^{s} d_{2222} w_{s}=f_{3} \\
B_{11}^{s} d_{111} u_{0}+\left(B_{12}^{s}+2 B_{66}^{s}\right) d_{122} u_{0}+\left(B_{12}^{s}+2 B_{66}^{s}\right) d_{112} v_{0} \\
+B_{22}^{s} d_{222} v_{0}-D_{11}^{s} d_{1111} w_{b}-2\left(D_{12}^{s}+2 D_{66}^{s}\right) d_{1122} w_{b} \\
-D_{22}^{s} d_{2222} w_{b}-H_{11}^{s} d_{1111} w_{s}-2\left(H_{12}^{s}+2 H_{66}^{s}\right) d_{1122} w_{s} \\
-H_{22}^{s} d_{2222} w_{s}+A_{55}^{s} d_{11} w_{s}+A_{44}^{s} d_{22} w_{s}=f_{4}
\end{gathered}
$$

where $\{f\}=\left\{f_{1}, f_{2}, f_{3}, f_{4}\right\}^{t}$ is a generalized force vector, $d_{i j}$, $d_{i j l}$ and $d_{i j l m}$ are the following differential operators:

$$
\begin{gathered}
d_{i j}=\frac{\partial^{2}}{\partial x_{i} \partial x_{j}}, d_{i j l}=\frac{\partial^{3}}{\partial x_{i} \partial x_{j} \partial x_{l}}, \\
d_{i j l m}=\frac{\partial^{4}}{\partial x_{i} \partial x_{j} \partial x_{l} \partial x_{m}}, d_{i}=\frac{\partial}{\partial x_{i}}, \quad(i, j, l, m=1,2) .
\end{gathered}
$$

The components of the generalized force vector $\{f\}$ are given by:

$$
\begin{aligned}
& f_{1}=\frac{\partial N_{x}^{T}}{\partial x}, f_{2}=\frac{\partial N_{y}^{T}}{\partial y}, f_{3}=q-\frac{\partial^{2} M_{x}^{b T}}{\partial x^{2}}-\frac{\partial^{2} M_{y}^{b T}}{\partial y^{2}} \\
& f_{4}=q-\frac{\partial^{2} M_{x}^{s T}}{\partial x^{2}}-\frac{\partial^{2} M_{y}^{s T}}{\partial y^{2}} .
\end{aligned}
$$

\section{The exact solution for FGM plates}

Generally, rectangular plates are classified according to used support type [32], [35] and [36]. The simple support boundary conditions are: $v_{0}=w_{b}=w_{s}=\frac{\partial w_{b}}{\partial y}=\frac{\partial w_{s}}{\partial y}=N_{x}=M_{x}^{b}=M_{x}^{s}=0$ at $x=0, a$,

$u_{0}=w_{b}=w_{s}=\frac{\partial w_{b}}{\partial x}=\frac{\partial w_{s}}{\partial x}=N_{y}=M_{y}^{b}=M_{y}^{s}=0$ at $y=0, b$,

It is considered here the exact solution of Eq. (28) for a simply supported FGM plate. To solve this problem, Navier assumes that the transverse mechanical and temperature loads, $q$ and $T_{i}$ are given as a double Fourier series as follows:

$$
\left\{\begin{array}{c}
q \\
T_{i}
\end{array}\right\}=\left\{\begin{array}{c}
q_{0} \\
t_{i}
\end{array}\right\} \sin (\lambda x) \sin (\mu y), \quad(i=1,2,3)
$$

Where $\lambda=\pi / a, \mu=\pi / b, q_{0}$ and $t_{i}$ are constants.

Following the procedure of Navier solution, we assume the following solution:

$$
\left\{\begin{array}{c}
u_{0} \\
v_{0} \\
w_{b} \\
w_{s}
\end{array}\right\}=\left\{\begin{array}{c}
U_{m n} \cos (\lambda x) \sin (\mu y) \\
V_{m n} \sin (\lambda x) \cos (\mu y) \\
W_{b} \sin (\lambda x) \sin (\mu y) \\
W_{s} \sin (\lambda x) \sin (\mu y)
\end{array}\right\},
$$

Where $U_{m n}, V_{m n}, W_{b}$ and $W_{s}$ are arbitrary parameters to determine under condition which the solution of the equation (34) satisfied equilibrium equations Eqs. (29-32). The following operator's equation is obtained:

$$
[\mathrm{K}]\{\Delta\}=\{f\},
$$

Where $\{\Delta\}=\left\{U_{m n}, V_{m n}, W_{b} W_{s}\right\}$ and $[\mathrm{K}]$ is the symmetrical matrix, in which:

$$
\begin{aligned}
\mathrm{K}_{11}= & -\left(A_{11} \lambda^{2}+A_{66} \mu^{2}\right) \\
\mathrm{K}_{12}= & -\lambda \mu\left(A_{12}+A_{66}\right) \\
\mathrm{K}_{13}= & \lambda\left[B_{11} \lambda^{2}+\left(B_{12}+2 B_{66}\right) \mu^{2}\right] \\
\mathrm{K}_{14}= & \lambda\left[B_{11}^{s} \lambda^{2}+\left(B_{12}^{s}+2 B_{66}^{s}\right) \mu^{2}\right] \\
\mathrm{K}_{22}= & -\left(A_{66} \lambda^{2}+A_{22} \mu^{2}\right) \\
\mathrm{K}_{23}= & \mu\left[\left(B_{12}+2 B_{66}\right) \lambda^{2}+B_{22} \mu^{2}\right] \\
\mathrm{K}_{24}= & \mu\left[\left(B_{12}^{s}+2 B_{66}^{s}\right) \lambda^{2}+B_{22}^{s} \mu^{2}\right] \\
\mathrm{K}_{33}= & -\left(D_{11} \lambda^{4}+2\left(D_{12}+2 D_{66}\right) \lambda^{2} \mu^{2}+D_{22} \mu^{4}\right) \\
\mathrm{K}_{34}= & -\left(D_{11}^{s} \lambda^{4}+2\left(D_{12}^{s}+2 D_{66}^{s}\right) \lambda^{2} \mu^{2}+D_{22}^{s} \mu^{4}\right) \\
\mathrm{K}_{44}= & -\left(H_{11}^{s} \lambda^{4}+2\left(H_{11}^{s}+2 H_{66}^{s}\right) \lambda^{2} \mu^{2}\right) \\
& -\left(H_{22}^{s} \mu^{4}+A_{55}^{s} \lambda^{2}+A_{44}^{s} \mu^{2}\right)
\end{aligned}
$$

The components of the generalized forces vector are given by:

$$
\begin{gathered}
f_{1}=\lambda\left(A^{T} t_{1}+B^{T} t_{2}+{ }^{a} B^{T} t_{3}\right), \\
f_{2}=\mu\left(A^{T} t_{1}+B^{T} t_{2}+{ }^{a} B^{T} t_{3}\right), \\
f_{3}=-q_{0}-h\left(\lambda^{2}+\mu^{2}\right)\left(B^{T} t_{1}+D^{T} t_{2}+{ }^{a} D^{T} t_{3}\right), \\
f_{4}=-q_{0}-h\left(\lambda^{2}+\mu^{2}\right)\left({ }^{s} B^{T} t_{1}+{ }^{s} D^{T} t_{2}+{ }^{s} F^{T} t_{3}\right) .
\end{gathered}
$$


Where:

$$
\begin{gathered}
\left\{A^{T}, B^{T}, D^{T}\right\}=\int_{-h / 2}^{h / 2} \bar{\alpha}(z)\left\{1, \bar{z}, \bar{z}^{2}\right\} d z \\
\left\{{ }^{a} B^{T},{ }^{a} D^{T}\right\}=\int_{-h / 2}^{h / 2} \bar{\alpha}(z) \bar{\Psi}(z)\{1, \bar{z}\} d z \\
\left\{{ }^{s} B^{T},{ }^{s} D^{T},{ }^{s} F^{T}\right\}=\int_{-h / 2}^{h / 2} \bar{\alpha}(z) \bar{\Psi}(z)\{1, \bar{z}, \bar{\xi}(z)\} d z
\end{gathered}
$$

In which: $\bar{z}=z / h, \bar{\alpha}(z)=\frac{E(z)}{1-v} \alpha(z), \bar{\Psi}(z)=\psi(z) / h$ and $\bar{\xi}(z)=\frac{1}{\pi} \sin \left(\frac{\pi z}{h}\right)$.

\section{Analytical validation and numerical results}

For the plate in FGM, the material properties used in the present study are:

- Metal (Aluminum):

$E_{M}=70(\mathrm{GPa}), v=0.3 ; \alpha_{M}=23 \times\left(10^{-6} / \mathrm{C}^{\circ}\right)$.

- Ceramics (Zirconia):

$E_{C}=151(\mathrm{GPa}), v=0.3 ; \alpha_{C}=10 \times\left(10^{-6} / \mathrm{C}^{\circ}\right)$.

Numerical results are presented in terms of non-dimensional stresses and deflection. The different non-dimensional parameters used are:

- The central deflection: $\bar{w}=\frac{10^{2} D}{a^{4} q 0} w\left(\frac{a}{2}, \frac{b}{2}\right)$

- Axial stress: $\bar{\sigma}_{x}=\frac{1}{10^{2} q 0} \sigma_{x}\left(\frac{a}{2}, \frac{b}{2}, \frac{h}{2}\right)$

- The transverse shear stress: $\bar{\tau}_{x z}=-\frac{1}{10 q 0} \tau_{x z}\left(0, \frac{b}{2}, 0\right)$

- The coordinate thickness: $\bar{z}=z / h, D=\frac{h^{3} E_{C}}{12\left(1-v^{2}\right)}$.

The numerical results are given and represented in Fig. 4-9 by using the present refined exponential shear deformation plate theory (RESDT), it does not require a shear factor of correction and the number of unknown functions for the present theory of a high order is only four. Noted that the factor of shear correction is taken $k=5 / 6$ in the first order shear deformation plate theory (FSDPT).

In Figures 8-9, it is important to observe that the stresses for a plate entirely in ceramics are not the same as for a plate entirely in metal. This is because the plate is subjected to a field of temperature.

The relation between the present theory and the various theories of high order shear deformations and first order and the classical plate theory (ESDPT, PSDPT, SSDPT, FSDPT, CPT) is illustrated in Fig. 4-9. These figures also give the effects ofthe variation of the volume fraction exponent values $p$ on the dimensionless center deflection and stresses of the FGM rectangular plate. It is clear that the deflection decreases as much as the side-to-thickness ratio $(a / h)$ increases.

Figures 4-6 shows an excellent agreement of this theory with the other high order shear deformation theories for a square FGM plate subjected to a mechanical load.

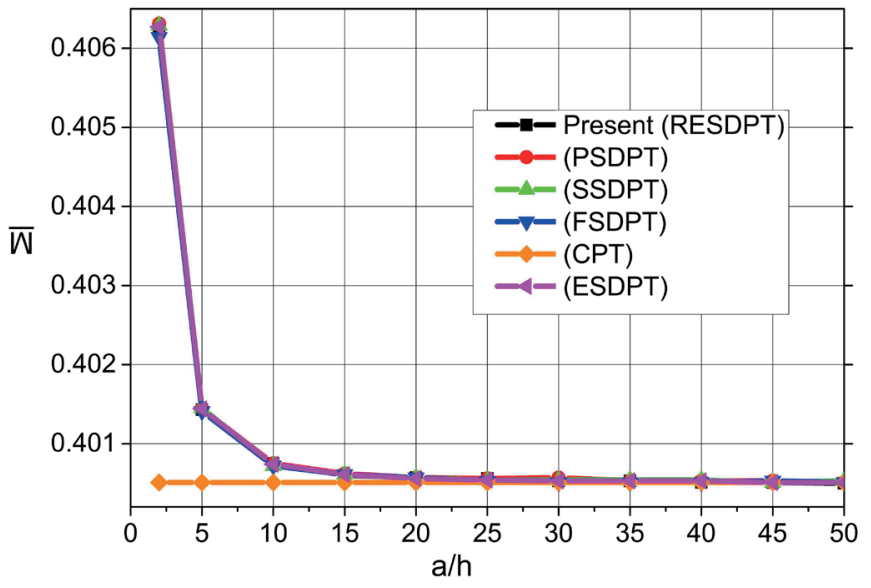

Fig. 4 Variation of the dimensionless center deflection $(\bar{W})$ through the thickness of a square FGM plate $(p=2)$ for various theories and different side-to-thickness ratio $(a / h)$ with $\left(q_{0}=100, t_{i}=0\right)$.

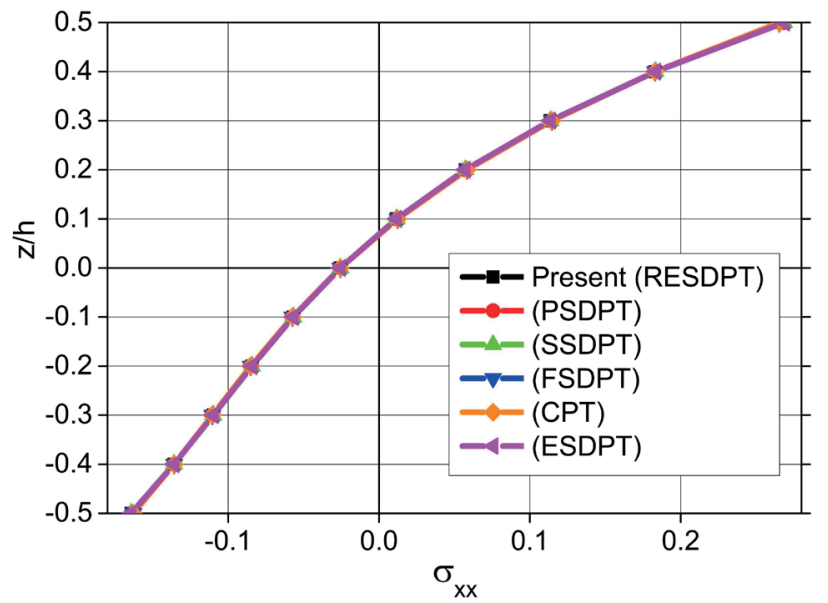

Fig. 5 Variation of dimensionless axial stress $\left(\bar{\sigma}_{x}\right)$ through the thickness of a square FGM plate $(p=2)$ for various theories with with $\left(q_{0}=100, t_{i}=0\right)$.



Fig. 6 Variation of dimensionless shear stress $\left(\bar{\tau}_{x z}\right)$ through the thickness of a square FGM plate $(p=2)$ for various theories with $\left(q_{0}=100, t_{i}=0\right)$.

Dimensionless axial stress $\left(\bar{\sigma}_{x}\right)$, is represented in Fig. 5 and Fig. 8. One can see that the maximum compressive stresses occur at a point near the upper surface while maximum tensile stresses are at a point close to the lower surface of the FGM plate.

Fig. 9 illustrate the dimensionless shear stress $\left(\bar{\tau}_{x z}\right)$ distributions through the thickness of a square and rectangular FGM plate under thermal loads. 


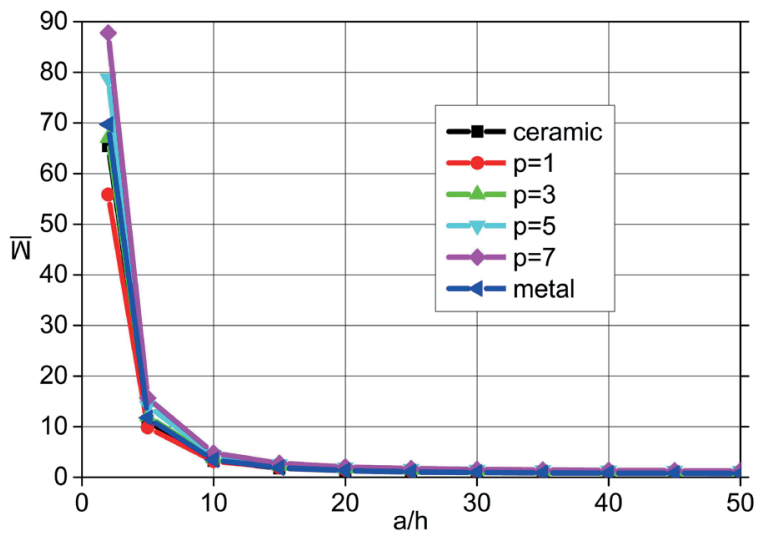

Fig. 7 Effect of the volume fraction exponent $p$ on the dimensionless center deflection $(\bar{W})$ of a rectangular FGM plate for different side-to-thickness ratio $(a / h)$ with $\left(q_{0}=100, t_{i}=10, b=2 a\right)$.

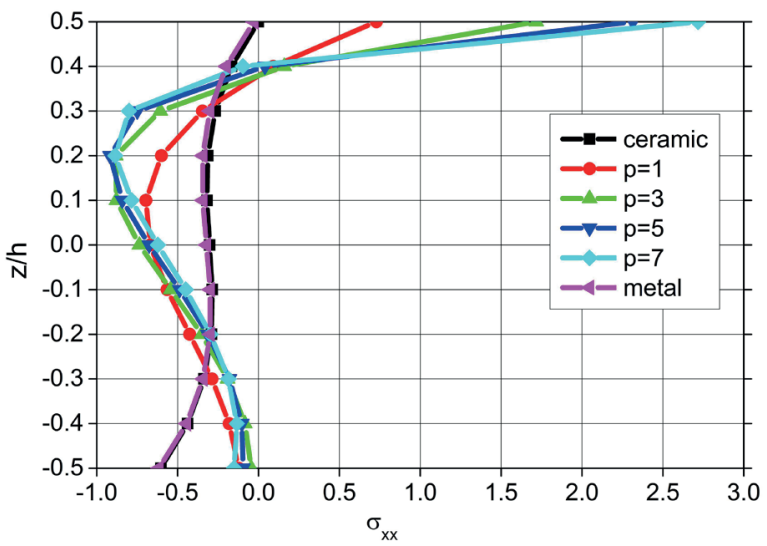

Fig. 8 Effect of the volume fraction exponent $p$ on dimensionless axial stress $\left(\bar{\sigma}_{x}\right)$ through-the-thickness of a rectangular FGM plate with $\left(q_{0}=100, t_{i}=10, b=2 a\right)$.



Fig. 9 Effect of the volume fraction exponent $p$ on the dimensionless shear stress $\left(\bar{\tau}_{x z}\right)$ through-the-thickness of a rectangular FGM plate with

$$
\left(q_{0}=100, t_{i}=10, b=2 a\right) \text {. }
$$

Maximum values of $\left(\bar{\tau}_{x z}\right)$ occur with $(\bar{z} \cong 0.1)$ of the FGM plate, not in the center of the plate as in the homogeneous case. The deflection and two axial stresses and shear stresses increase with as the thermal load increases.

The effect of the mechanical and thermal loads is taken into consideration. The deflection is larger for plates subjected to thermal load only whereas it is smaller for plates subjected to mechanical load only. With the inclusion of all loads $\left(q_{0}=100\right.$, $\left.t_{1}=t_{2}=t_{3}=10\right)$, the deflection decreases as $a / h$ increase.



Fig. 10 Effect of the thermal field on the dimensionless center deflection $(\bar{W})$ of a rectangular FGM plate for different side-to-thickness ratio $(a / h)$ with $\left(p=2, q_{0}=100, b=2 a\right)$.

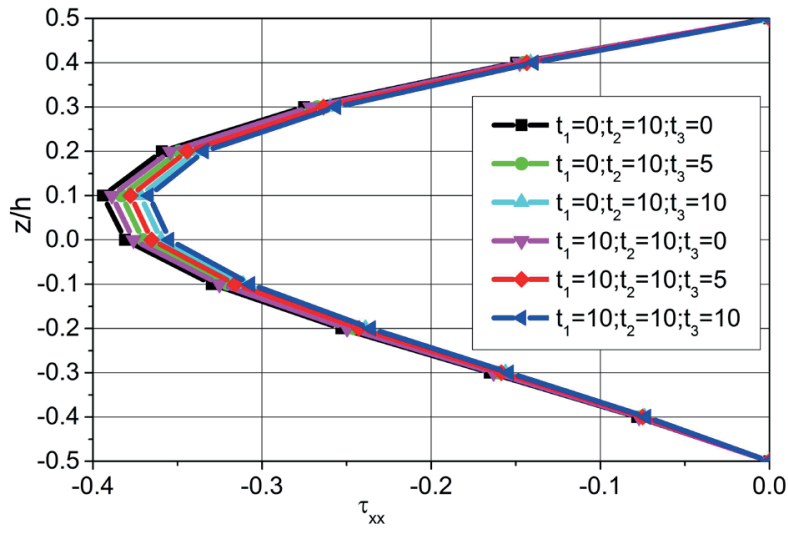

Fig. 11 Effect of the thermal field on dimensionless axial stress $\left(\bar{\sigma}_{x}\right)$ throughthe-thickness of a rectangular FGM plate with $\left(p=2, q_{0}=100, b=2 a\right)$.



Fig. 12 Effect of the thermal field on the dimensionless shear stress $\left(\bar{\tau}_{x z}\right)$ through-the-thickness of a rectangular FGM plate with $\left(p=2, q_{0}=100, b=2 a\right)$.

Finally, Figures 10-12 show the effect of the thermal field on the deflection and stresses. For FGM plates subjected to thermal load, the deflection may be stable for all values of $a / h \geq 5$.

The deflection and both axial stresses and shear stresses increase with the increase of the thermal load $t_{3}$.

The figures emphasize the great influence played by the different thermal and bending loads on the analyzed axial and transverse shear stresses. 


\section{Conclusions}

In this work, we presented the numerical results of static bending analysis in composite materials with specific properties "Case of a typical FGM (ceramic / metal)" in thermal environments, using the refined exponential shear deformation plate theory (RESDPT).

- The present theory has a strong similarity to classical plate theory in many aspects, it does not require a shear correction factor, and gives an exponential description of the shear stresses across the thickness while satisfying the condition of zero shear stress on the free edges.

- In addition, the present theory shows an excellent agreement with the ESDPT theory [20], the conventional SSDPT theory $[24,25]$ and the parabolic shear deformation plate theory PSDPT [18].

- Gradients in material properties play an important role in determining the response of FGM plates.

- All comparative studies have shown that the deflections and stresses obtained using the present refined theory (with four unknowns) and other high-order shear deformation theories (five unknowns) are almost identical.

Therefore, it can be said that the proposed theory is not only accurate but also simple to study and analyze the thermo-mechanical bending response of thick FGM plates. Composite materials with gradients of properties made from a ceramic / metal mix capable of resist extreme temperatures. The mixture of the ceramic and metal with continuously varying volume fraction can eliminate interface problems of sandwich plates and thus the stresses distributions are smooth.

This theory can be implemented via a displacement based finite element method as is shown by [37]. For this, the variational statement in Eq. (19) requires that the bending and shear components of transverse displacement $w_{b}$ and $w_{s}$ be twice differentiable and $\mathrm{C}^{1}$-continuous, whereas the axial displacements $u_{0}$ and $v_{0}$ must be only once differentiable and $\mathrm{C}^{0}$-continuous. Thus, a finite element formulation of the present theory will be considered in the future work to solve more complex problems.

\section{References}

[1] Yamanouchi, M., Koizumi, M., Hirai, T., Shiota, I. (Eds.) "Proceedings of the First International Symposium on Functionally Gradient Materials". FGM '90. Japan, Oct. 8-9. p. 379. 1990.

[2] Koizumi, M. "FGM activities in Japan". Composites Part B: Engineering, 28(1-2), pp. 1-4. 1997.

https://doi.org/10.1016/S1359-8368(96)00016-9

[3] Suresh, S., Mortensen, A. "Fundamentals of functionally graded materials: processing and thermomechanical behaviour of graded metals and metal-ceramic composites". IOM Communications Ltd., Cambridge, UK. 1998.

[4] Pindera, M-J., Arnold, S. M., Aboudii, J., Hui, D. "Use of Composites in Functionally Graded Materials". Composites Engineering, 4(1), pp. vii-ix (Foreword), 1994.
[5] Pindera, M.-J., Aboudi, J., Arnold, S. M., Jones, W. F. "Use of composites in multi-phased and functionally graded materials". Composites Engineering, 5(7), pp. vii-ix (Foreword), 1995.

[6] Markworth, A. J., Ramesh, K. S., Parks Jr, W. P. "Modelling studies applied to functionally graded materials". Journal of Materials Science, 30(9), pp. 2183-2193. 1995.

https://doi.org/10.1007/BF01184560

[7] Miyamoto, Y., Kaysser, W. A., Rabin, B. H., Kawasaki, A., Ford, R. G. "Functionally Graded Materials: Design, Processing and Applications". Kluwer Academic, Dordrecht. 1999. https://doi.org/10.7569/RAA.2014.097301

[8] Paulino, G. H., Jin, Z.-H., Dodds, R. H. "Failure of Functionally Graded Materials". In: Reference Module in Materials Science and Materials Engineering, Chapter 2.13. pp. 607-644. Elsevier, 2017. https://doi.org/10.1016/B978-0-12-803581-8.00875-4

[9] Noda, N. "Thermal stresses in functionally graded materials". Journal of Thermal Stresses, 22(4-5), pp. 447-512. 1999. https://doi.org/10.1080/014957399280841

[10] Van der Biest, O., Gasik, M. Vleugels, J. (Eds.) "Proceedings of the Eighth International Symposium on Multifunctional and Functionally Graded Materials". (FGM 2004). Jul. 11-14, Leuven, Belgium, 2004.

[11] Reddy, J. N. "Analysis of functionally graded plates". International Journal for Numerical Methods in Engineering, 47(1-3), pp. 663-684. 2000.

[12] Reddy, J. N., Chin, C. D. "Thermomechanical Analysis of Functionally Graded Cylinders and Plates". Journal of Thermal Stresses, 21(6), pp. 593-626. 1998.

https://doi.org/10.1080/01495739808956165

[13] Vel, S. S., Batra, R. C. "Exact Solution for Thermoelastic Deformations of Functionally Graded Thick Rectangular Plates". AIAA Journal, 40(7), pp. 1421-1433. 2002.

https://doi.org/10.2514/2.1805

[14] Vel, S. S., Batra, R. C. "Three-dimensional analysis of transient thermal stresses in functionally graded plates". International Journal of Solids and Structures, 40(25), pp. 7181-7196. 2003.

https://doi.org/10.1016/S0020-7683(03)00361-5

[15] Cheng, Z.-Q., Batra, R. C. "Three-dimensional thermoelastic deformations of a functionally graded elliptic plate". Composites Part B: Engineering, 31(2), pp. 97-106. 2000.

https://doi.org/10.1016/S1359-8368(99)00069-4

[16] Swaminathan, K., Sangeetha, D. M. "Thermal Analysis of FGM Plates - A Critical Review of Various Modelling Techniques and Solution Methods". Composite Structures, 160, pp. 43-60. 2017.

https://doi.org/10.1016/j.compstruct.2016.10.047

[17] Aydogdu, M. "Comparison of Various Shear Deformation Theories for Bending, Buckling, and Vibration of Rectangular Symmetric Cross-ply Plate with Simply Supported Edges". Journal of Composite Materials, 40(23), pp. 2143-2155. 2006. https://doi.org/10.1177/0021998306062313

[18] Reddy, J. N. "A Simple Higher-Order Theory for Laminated Composite Plates". Journal of Applied Mechanics, 51(4), pp. 745-752. 1984. https://doi.org/10.1115/1.3167719

[19] Soldatos, K. P. "A transverse shear deformation theory for homogenous monoclinic plates". Acta Mechanica, 94(3-4), pp. 195-220. 1992. https://doi.org/10.1007/BF01176650

[20] Karama M, Afaq K. S., Mistou S. "Mechanical behavior of laminated composite beam by the new multilayered laminated composite structures model with transverse shear stress continuity". International Journal of Solids and Structures, 40(6), pp. 1525-1546. 2003. https://doi.org/10.1016/S0020-7683(02)00647-9 
[21] Osofero, A. I., Vo, T. P., Nguyen, T.-K., Lee, J. "Analytical solution for vibration and buckling of functionally graded sandwich beams using various quasi-3D theories". Journal of Sandwich Structures and Materials, 18(1), pp. 3-29. 2016. https://doi.org/10.1177/1099636215582217

[22] Zhang, D.-G., Zhou, Y.-H. "A theoretical analysis of FGM thin plates based on physical neutral surface". Computational Materials Science, 44(2), pp. 716-720. 2008.

https://doi.org/10.1016/j.commatsci.2008.05.016

[23] Reissner, E. "On transverse bending of plates, including the effect of transverse shear deformation". International Journal of Solids Structures, 11(5), pp. 569-573. 1975. https://doi.org/10.1016/0020-7683(75)90030-X

[24] Touratier, M. "An efficient standard plate theory". International Journal of Engineering Science, 29(8), pp. 901-916. 1991. https://doi.org/10.1016/0020-7225(91)90165-Y

[25] Zenkour, A. M. "The refined sinusoidal theory for FGM plates on elastic foundations". International Journal of Mechanical Sciences, 51(11-12), pp. 869-880. 2009. https://doi.org/10.1016/j.ijmecsci.2009.09.026

[26] Delale, F., Erdogan, F. "The crack problem for a nonhomogeneous plane". Journal of Applied Mechanics, 50(3), pp. 609-614. 1983. https://doi.org/10.1115/1.3167098

[27] Wattanasakulpong, N., Ungbhakorn, V. "Linear and nonlinear vibration analysis of elastically restrained ends FGM beams with porosities". Aerospace Science and Technology, 32(1), pp. 111-120. 2014. https://doi.org/10.1016/j.ast.2013.12.002

[28] Yahia, S. A., Atmane, H. A., Houari, M. S. A., Tounsi, A. "Wave propagation in functionally graded plates with porosities using various higherorder shear deformation plate theories". Structural Engineering and Mechanics, 53(6), pp. 1143-1165. 2015. https://doi.org/10.12989/sem.2015.53.6.1143
[29] Simsek, M. "Fundamental frequency analysis of functionally graded beams by using different higher-order beam theories". Nuclear Engineering and Design, 240(4), pp. 697-705. 2010. https://doi.org/10.1016/j.nucengdes.2009.12.013

[30] Duc, N. D., Cong, P. H. "Nonlinear postbuckling of an eccentrically stiffened thin FGM plate resting on elastic foundations in thermal environments". Thin-Walled Structures, 75, pp. 103-112. 2014. https://doi.org/10.1016/j.tws.2013.10.015

[31] Wakashima, K., Hirano, T., Niino, M. "Functionally Gradient Materials (FGM) Architecture: A New Type of Ceramic-Metal Assemblage Designed for Hot Structural Components". In: Space applications of advanced structural materials, SP-303, pp. 97-102. 1990.

[32] Reddy. J. N. "Mechanics of Laminated Composite Plates and Shells: theory and analysis". Boca Raton, FL: CRC Press. 1997.

[33] Marur, P. R. "Fracture behaviour of functionally graded materials". PhD thesis, Auburn University. Publication number: AAI9931107 ISBN: 9780599312609. 1999.

[34] Praveen, G. N., Reddy, J. N. "Nonlinear transient thermoelastic analysis of functionally graded ceramic-metal plates". International Journal of Solids and Structures, 35(33), pp. 4457-4476. 1998. https://doi.org/10.1016/S0020-7683(97)00253-9

[35] Bouderba, B., Houari, M. S. A., Tounsi, A. "Thermomechanical bending response of FGM thick plates resting on winkler-pasternak elastic foundations". Steel and Composite Structures, 14(1), pp. 85-104. 2013. https://doi.org/10.12989/scs.2013.14.1.085

[36] Khdeir, A. A., Reddy, J. N. "Exact solutions for the transient response of symmetric cross-ply laminates using a higher-order plate theory". Composites Science and Technology, 34(3), pp. 205-224. 1989. https://doi.org/10.1016/0266-3538(89)90029-8

[37] Vo, T. P., Thai, H.-T. "Free vibration of axially loaded rectangular composite beams using refined shear deformation theory". Composite Structures, 94(11), pp. 3379-3387. 2012.

https://doi.org/10.1016/j.compstruct.2012.05.012 